\title{
A Cloud and Precipitation Feature Database from Nine Years of TRMM Observations
}

\author{
Chuntao LiU and Edward J. ZiPSER \\ Department of Meteorology, University of Utah, Salt Lake City, Utah \\ DANIEl J. CECIL \\ Earth System Science Center, University of Alabama in Huntsville, Huntsville, Alabama \\ STEPHEN W. NESBitT \\ Department of Atmospheric Sciences, University of Illinois at Urbana-Champaign, Urbana, Illinois \\ STEVEN SHERWOOD \\ Department of Geology and Geophysics, Yale University, New Haven, Connecticut
}

(Manuscript received 4 October 2007, in final form 14 February 2008)

\begin{abstract}
An event-based method of analyzing the measurements from multiple satellite sensors is presented by using observations of the Tropical Rainfall Measuring Mission (TRMM) precipitation radar (PR), Microwave Imager (TMI), Visible and Infrared Scanner (VIRS), and Lightning Imaging System (LIS). First, the observations from PR, VIRS, TMI, and LIS are temporally and spatially collocated. Then the cloud and precipitation features are defined by grouping contiguous pixels using various criteria, including surface rain, cold infrared, or microwave brightness temperature. The characteristics of measurements from different sensors inside these features are summarized. Then, climatological descriptions of many properties of the identified features are generated. This analysis method condenses the original information of pixellevel measurements into the properties of events, which can greatly increase the efficiency of searching and sorting the observed historical events. Using the TRMM cloud and precipitation feature database, the regional variations of rainfall contribution by features with different size, intensity, and PR reflectivity vertical structure are shown. Above the freezing level, land storms tend to have larger $20-\mathrm{dB} Z$ area and reach higher altitude than is the case for oceanic storms, especially those land storms over central Africa. Horizontal size and the maximum reflectivity of oceanic storms decrease with altitude. For land storms, these intensity measures increase with altitude between $2 \mathrm{~km}$ and the freezing level and decrease more slowly with altitude above the freezing level than for ocean storms.
\end{abstract}

\section{Introduction}

As the quantity of satellite observations available for cloud and precipitation research continues to increase, more efficient methods for analysis and sorting of useful information from these observations are becoming essential. In the traditional method, the orbital pixellevel observations are statistically summarized onto

Corresponding author address: Dr. Chuntao Liu, Department of Meteorology, University of Utah, 135S 1460E Rm. 819, Salt Lake City, UT 84112-0110.

E-mail: liu.c.t@utah.edu horizontal grids and provide information on their global distribution. However, gridded averaged data products cannot be used to retrieve information on individual events. It is difficult to quickly search and fetch information of historical weather events either from these grid-level datasets or from original pixel-level observations because of the huge amount of data. One solution is to summarize observations for individual cloud or precipitation events.

Event-based analysis methods are not new. There were studies of clouds conducted by grouping pixels with infrared brightness temperatures colder than certain criteria (e.g., Mapes and Houze 1992; Liu et al. 
1995; Chen et al. 1996) and studies of precipitation systems by grouping pixels with cold microwave brightness temperature (e.g., Mohr and Zipser 1996; Toracinta and Zipser 2001) or by grouping pixels with valid precipitation radar echoes (e.g., Geerts 1998; Cifelli et al. 2007). However, when several satellite instruments target the same object, different instruments and their measurands have their own characteristics and give different perspectives. Examples include Tropical Rainfall Measuring Mission (TRMM; Kummerow et al. 1998) and A-Train (Stephens et al. 2002) observations. On the TRMM satellite, the precipitation radar (PR) can provide detailed vertical distribution of precipitationsized particles inside systems. The TRMM Microwave Imager (TMI) can provide some information on vertically integrated ice and water path. The Visible and Infrared Scanner (VIRS) can provide information on cloud-top temperature and reflectance. At the same time, the Lightning Imaging Sensor (LIS) estimates lightning-flash rates. How to analyze and efficiently utilize all this information is a scientific challenge.

One way to summarize the precipitation events from the TRMM dataset is to define precipitation features (PFs; Nesbitt et al. 2000). This method groups the pixels with near-surface PR reflectivity $\geq 20 \mathrm{dBZ}$ or icescattering signal defined by TMI $85-\mathrm{GHz}$ polarizationcorrected temperature (PCT; Spencer et al. 1989) $\leq 250 \mathrm{~K}$. Using this definition and the similar-featuregrouping concept, results have included rainfallestimate validation, diurnal cycle of precipitation systems (Nesbitt and Zipser 2003), global distribution of storms with LIS-detected lightning (Cecil et al. 2005), deep convection reaching the tropical tropopause layer (Liu and Zipser 2005), rainfall production and convective organization (Nesbitt et al. 2006), and the categorization of extreme thunderstorms by their intensity proxies (Zipser et al. 2006).

However, this particular definition of PFs has some disadvantages that limit its applicability to wider research areas. First, the PFs defined by Nesbitt et al. (2000) exclude some light-rain area with surface reflectivity between the PR minimum detectable signal of $17-18 \mathrm{~dB} Z$ and $20 \mathrm{~dB} Z$ and TMI $85-\mathrm{GHz}$ PCT $>250 \mathrm{~K}$. Also, some PFs over nonraining areas with cold 85$\mathrm{GHz}$ PCT are artifacts resulting from low surface emissivity from snow cover, especially over high terrain. Second, the precipitating area usually is only a small part of a cloud system. There exist large areas of cold anvil clouds neither with surface radar echoes nor with cold ice-scattering signals (Liu et al. 2007). Thus, this PF definition cannot be used to study the entire cloud system and especially the relation between the precipi- tation and the radiative impacts of these cloud systems. Third, it is inappropriate to compare conditional rain rates from the PR and TMI in a feature defined using information from both PR and TMI measurements.

This paper introduces a method that reduces the above limitations by using multiple definitions of the cloud and precipitation features to analyze TRMM data. A database is constructed with features identified from nine years of TRMM observations. Then, the regional variations of the cloud and precipitation features' rainfall contributions and their convective intensity inferred from vertical reflectivity structures are studied using the database.

\section{Data and methods}

The schematic diagram of the TRMM cloud and precipitation feature database with three levels of TRMM data processing is shown in Fig. 1. First, the measurements from multiple instruments are temporally and spatially collocated. Then the cloud and precipitation features are defined with different criteria using these collocated data. Using the characteristics of defined features, global climatological descriptions of cloud and precipitation feature populations, occurrences, and other statistics are generated. This section introduces the methods used in these three steps.

\section{a. Level 1: Collocation of measurements from different instruments}

To collocate the observations from different instruments, a common sample volume and unified coordinates have to be defined. Here we use measurements only in the PR swath and choose coordinates of the PR pixels as the common grids for collocation. The collocated TRMM datasets include version-6 VIRS radiances (1B01), TMI brightness temperatures (1B11), rainfall retrievals from TMI (2A12; Kummerow et al. 2001), stratiform and convective rainfall categorizations (2A23; Steiner et al. 1995; Awaka et al. 1998), rainfall retrieval from PR (2A25; Iguchi et al. 2000), and LIS flashes (http://daac.gsfc.nasa.gov/data/datapool/ $\mathrm{TRMM} /)$.

Because both VIRS and PR scan through nadir, the brightness temperatures at five VIRS channels at each PR pixel are calculated from radiances at the nearestneighbor VIRS pixel. Each LIS flash is also assigned to a PR pixel by using the nearest-neighbor method. Because TMI scans conically and the measurements at different wavelengths have different resolutions, the collocation between TMI and PR measurements is not 


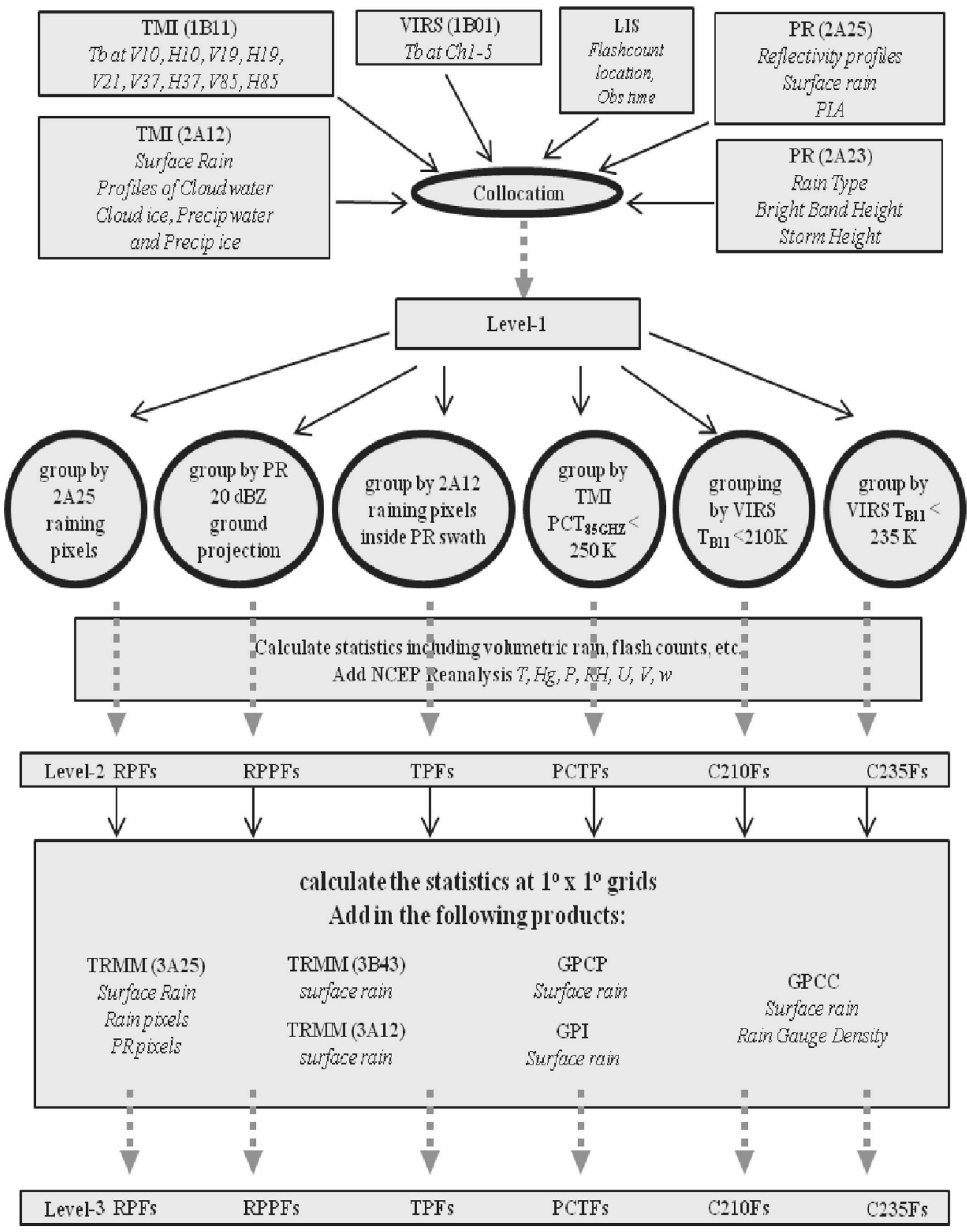

FIG. 1. Flowchart of three levels of the University of Utah TRMM feature database. Here "TMI Tb at V10, H10, V19, H19, V21, V37, H37, V85, and H85" stands for the vertical and horizontal polarized 10-, 19-, 21-, 37-, and 85-GHz brightness temperatures. "VIRS Tb at Ch 1-5" stands for the VIRS observed brightness temperatures at 0.65-, 1.61-, 3.75-, 10.8-, and 12.0- $\mu$ m wavelengths. This dataset is open to the public; interested persons are encouraged to contact the authors for details. 


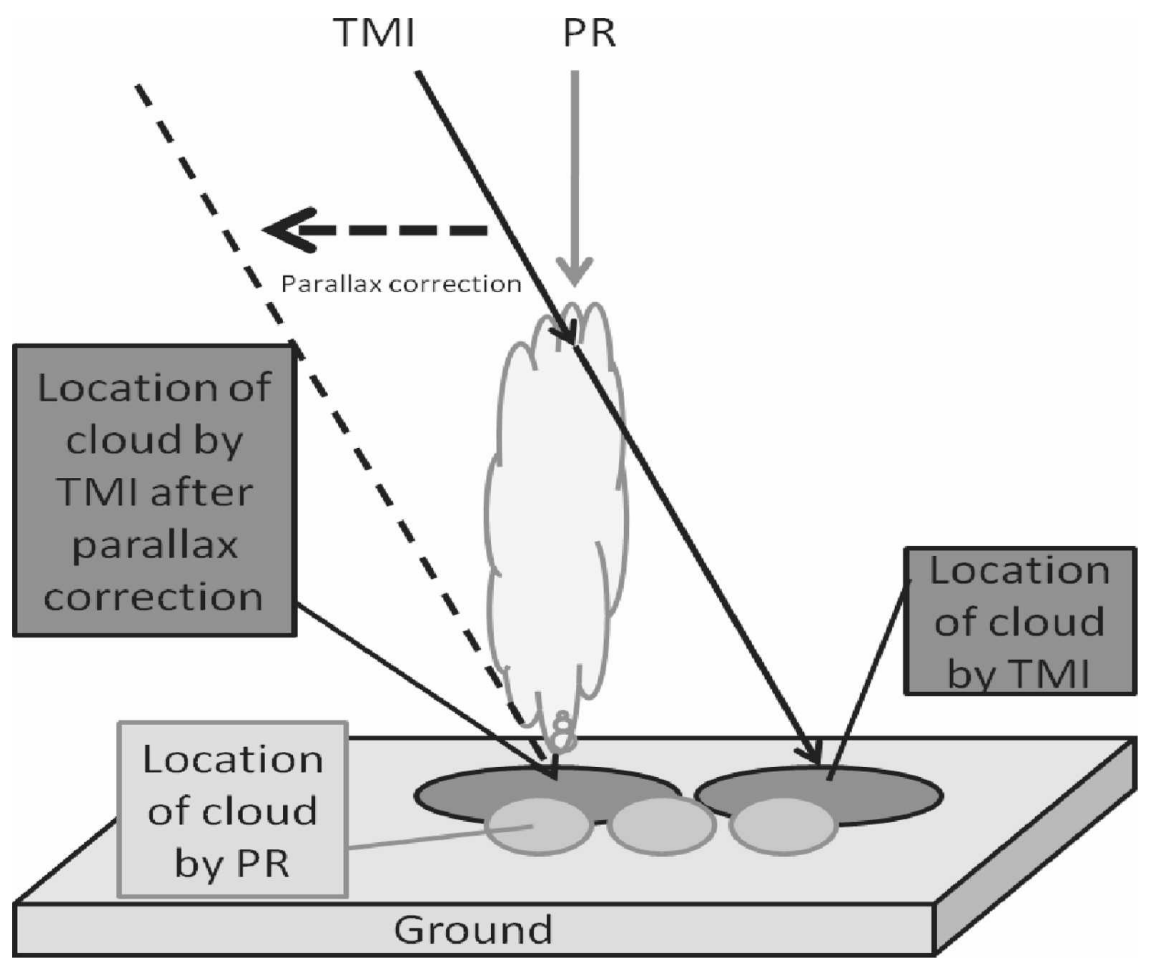

FIG. 2. Schematic diagram of parallax correction. When there are hydrometeors at high altitude, the TMI microwave scattering signal would appear as from the nearby surface because of the $52^{\circ}$ slant angle. To account for this effect and to collocate better with the nadir observations, the TMI data coordinates are simply moved backward (or forward depending on the orientation of the satellite) for one scan.

as simple. TRMM 1B11 orbital granule data are stored in two resolutions. One is the low resolution with pixel area of approximately $96 \mathrm{~km}^{2}(13.0 \mathrm{~km} \times 7.3 \mathrm{~km})$ before the TRMM satellite orbit boost in August of 2001 and approximately $110 \mathrm{~km}^{2}(13.0 \mathrm{~km} \times 8.3 \mathrm{~km})$ after the boost for 10-, 19-, 21-, and 37-GHz brightness temperatures. The other is the high resolution with pixel size of approximately $48 \mathrm{~km}^{2}(13.0 \mathrm{~km} \times 3.65 \mathrm{~km})$ before the boost and approximately $55 \mathrm{~km}^{2}(13.0 \mathrm{~km} \times$ $4.2 \mathrm{~km}$ ) after the boost for $85-\mathrm{GHz}$ brightness temperatures and rain retrievals. Note that these are the sizes of the areas between each measurement location; the instrument field of view is smaller than the distance between scans for $85 \mathrm{GHz}$ while the field of view becomes sequentially larger for each of the lower frequencies (Kummerow et al. 1998) to the point at which the 10$\mathrm{GHz}$ channel is much larger than the gap between lowresolution scans (e.g., oversampling). The collocations are performed on both resolutions inside the PR swath. Using the nearest-neighbor method, each PR pixel is assigned a corresponding TMI pixel with parameters from 1B11 and 2A12. Because of the differing spatial resolutions, multiple $\mathrm{PR}$ pixels are assigned to a single TMI pixel.
Because TMI scans with a conical $52.8^{\circ}$ incidence angle, there is usually a collocation problem if the microwave ice-scattering signals are from elevated hydrometeors. For example, as shown in Fig. 2, the scattering signal from ice particles at about $12.7 \mathrm{~km}$ would seem as from the neighbor pixel in the previous scan. To account for this, we used a rough parallax correction method that simply moves the coordinates of TMI data backward (or forward depending on the orientation of the scan) for one scan as shown in Fig. 2. After this correction, there are better location correspondences between PR and TMI observations for deep convective cells with strong ice scattering. However, the correspondence for shallow precipitation inevitably becomes worse because of this overcorrection. This situation leads to problems when summarizing TMI measurements inside a small and shallow precipitation system. Limiting such problems is one reason why we focus on comparing properties of larger cloud and precipitation events, as opposed to comparing individual pixels. After collocation, the selected parameters (some are listed in section 2b; Liu 2007) are saved into compressed orbital files in Hierarchical Data Format 4 (HDF4) format as level-1 products. 
TABLE 1. Definition of precipitation and cloud features from 1998 to 2006 in the University of Utah TRMM database. The populations of features are also listed.

\begin{tabular}{lllr}
\hline \hline Acronyms & \multicolumn{1}{c}{ Definition } & \multicolumn{1}{c}{ Criteria } & Population (millions) \\
\hline RPF & Radar precipitation feature & Pixels with 2A25 rainfall rate $>0$ & 78.2 \\
RPPF & Radar projection precipitation Feature & Pixels with 20 dBZ anywhere above ground & 68.6 \\
TPF & TMI precipitation feature & Pixels with 2A12 rainfall rate $>0$ & 14.8 \\
PCTF & TMI cold 85-GHZ PCT feature & Pixels with 85-GHZ PCT $<250 \mathrm{~K}$ & 6.2 \\
$\mathrm{C} 210 \mathrm{~F}$ & Cloud features with 210 K & VIRS $T_{\mathrm{B} 11}<210 \mathrm{~K}$ & 2.8 \\
$\mathrm{C} 235 \mathrm{~F}$ & Cloud features with 235 K & VIRS $T_{\mathrm{B} 11}<235 \mathrm{~K}$ & 20.5 \\
$\mathrm{C} 273 \mathrm{~F}$ & Cloud features with 273 K & VIRS $T_{\mathrm{B} 11}<273 \mathrm{~K}$ & 77.2 \\
\hline
\end{tabular}

\section{b. Level 2: Defining cloud and precipitation features}

Using the collocated level-1 products, a set of cloud and precipitation features is defined using the criteria listed in Table 1. In addition to the prior PF definition (Nesbitt et al. 2000), two "pure" precipitation feature definitions are introduced by contiguous 2A25 nearsurface raining pixels (RPFs) and contiguous $2 \mathrm{~A} 12$ surface raining pixels (TPFs). To fully utilize the threedimensional information from PR reflectivity profiles, radar projection precipitation features (RPPFs) are introduced by grouping the area of ground projection of radar reflectivity greater than $20 \mathrm{~dB} Z$, which includes thick anvils aloft. Cold PCT features (PCTFs) are also defined by pixels with $85-\mathrm{GHz} \mathrm{PCT}<250 \mathrm{~K}$, for continuity with the longer record of Special Sensor Microwave Imager measurements. Cloud features are defined by using VIRS $10.8-\mu \mathrm{m}$ brightness temperature $\left(T_{\mathrm{B} 11}\right)<210(\mathrm{C} 210 \mathrm{~F}), 235(\mathrm{C} 235 \mathrm{~F})$, and $273(\mathrm{C} 273 \mathrm{~F}) \mathrm{K}$. Characteristics of features are summarized from measurements and retrievals from PR, TMI, VIRS, and LIS at the grouped pixels. In addition to the time and centroid location, some of the major parameters stored are listed below [details are given in Liu (2007)]:

- From PR algorithms 2A25 and 2A23, we calculate stratiform and convective rain area and volume $(\mathrm{mm}$ $\mathrm{h}^{-1} \mathrm{~km}^{2}$ ) from near-surface rain-rate retrieval, maximum height of 20,30 , and $40 \mathrm{~dB} Z$, vertical profile of maximum reflectivity with $0.5-\mathrm{km}$ resolution, and vertical profile of $20-\mathrm{dB} Z$ area with $1-\mathrm{km}$ resolution. The vertical profiles are calculated after interpolating the 2A25 attenuation-corrected reflectivity factor from slant-path bins to each vertical level relative to the earth's surface.

- From TMI algorithm 1B11 and 2A12, we calculate rain area and volume, minimum $37-$ and $85-\mathrm{GHz}$ PCTs, and area of $85-\mathrm{GHz}$ PCT $<250,200,150$, and $100 \mathrm{~K}$.

- From VIRS algorithm 1B01, we calculate minimum $T_{\mathrm{B} 11}$ area of $T_{\mathrm{B} 11}<210,235$, and $273 \mathrm{~K}$ and median value of brightness temperature at five wavelengths.

- From LIS, we accumulate the lightning-flash count and view time (duration of observation, normally around $80 \mathrm{~s}$ ) for the feature. Together, these yield a flash rate.

- To examine the environment of a cloud or precipitation feature, vertical profiles of temperature, geopotential height, wind, and humidity are extracted from the 6-hourly $2.5^{\circ} \times 2.5^{\circ}$ National Centers for Environmental Prediction (NCEP) reanalysis dataset (Kalnay et al. 1996; Kistler et al. 2001) for each feature with at least four PR pixels. First we temporally interpolate the NCEP data to the feature time. Then the data at the nearest neighbor of NCEP grid to the feature center are selected. Because of the coarse temporal and spatial resolution of NCEP reanalysis, and also because we do not take care to select a grid point that is representative of "inflow air" for each feature, these data should be used with caution.

An example of feature definitions for a severe storm over Oklahoma (Zipser et al. 2006) and some parameters in the defined RPPF are shown in Fig. 3. In this case, there were large areas of thick anvil aloft (Figs. $3 \mathrm{~b}, \mathrm{e})$ and large areas of cold clouds, without a strong ice-scattering signal (Fig. 3d) and hardly any surface rain (Fig. 3a). The old precipitation feature definition would mostly neglect the information about the anvil cloud. However, the detailed vertical distribution of 20$\mathrm{dBZ}$ area can be summarized in RPPFs (Fig. 3f). As shown in Table 2, the system can be described more comprehensively with multiple feature definitions. For example, the ratio from the large cold cloud area to surface raining area can be described by cold cloud features $(\mathrm{C} 210, \mathrm{C} 235 \mathrm{~F}$, and $\mathrm{C} 273 \mathrm{~F})$; the differences between $2 \mathrm{~A} 25$ and $2 \mathrm{~A} 12$ rain volume may be used to validate the performance of rain retrieval algorithms, and so on.

The original orbital level-1 data have a typical file size of about 200 megabytes. However, the information of the observed events in the orbit can be condensed 

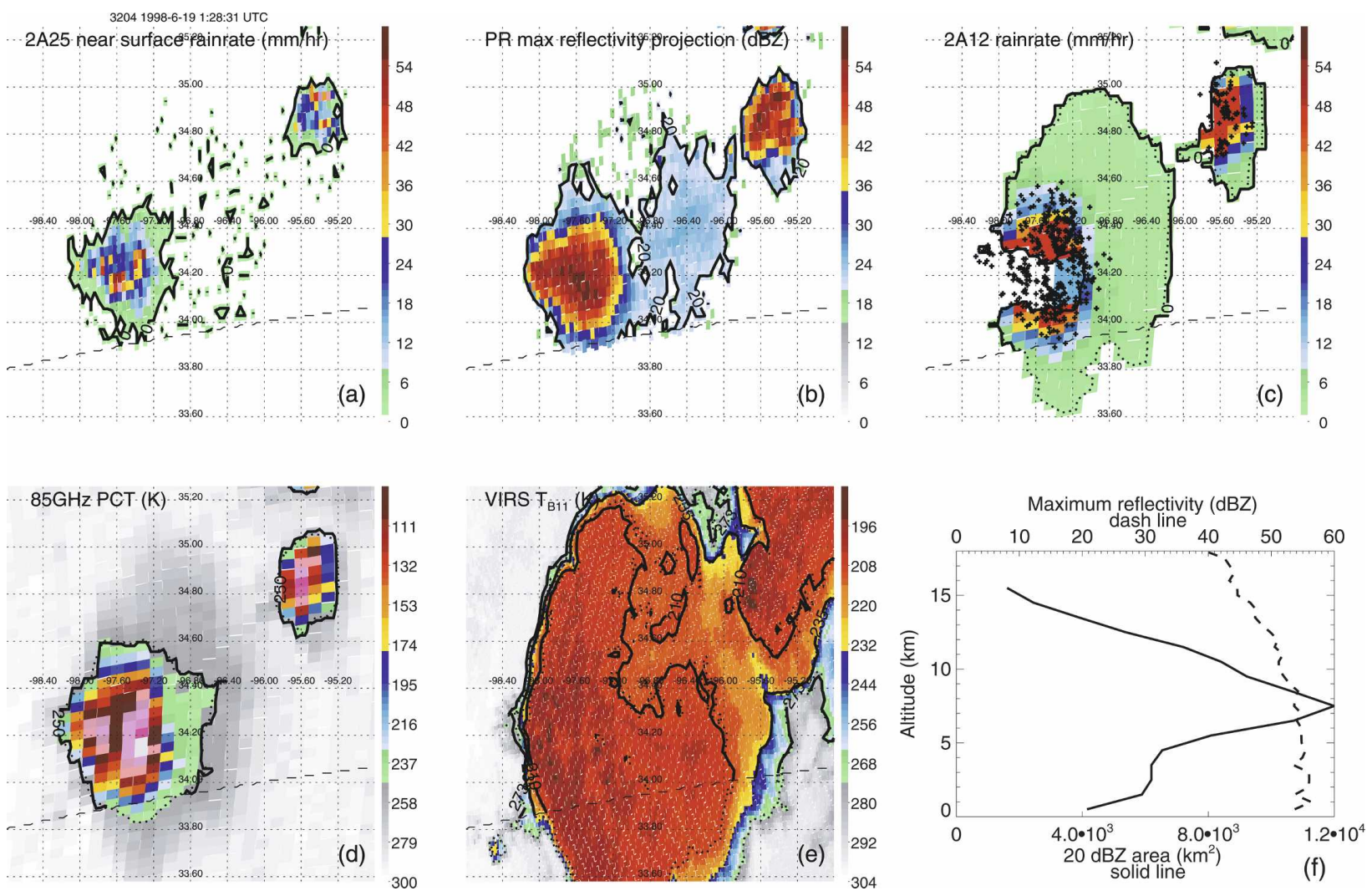

FIG. 3. Demonstration of the feature types using a severe-hailstorm case (Zipser et al. 2006). (a) 2 A25 near-surface rainfall rate. RPF is defined by the area with rain shown by black contour. (b) The PR maximum-reflectivity ground projection. RPPF is defined by area with $20 \mathrm{~dB} Z$ shown by black contour. (c) $2 \mathrm{~A} 12$ surface rainfall rate. TPF is defined by area with rain shown by black contour. Black dots are the location of flashes detected by LIS. (d) TMI $85-\mathrm{GHz}$ PCT. PCTF is shown by $250-\mathrm{K}$ contour line. (e) VIRS $T_{\mathrm{B} 11} \mathrm{C} 210 \mathrm{~F}$, $\mathrm{C} 235 \mathrm{~F}$, and $\mathrm{C} 273 \mathrm{~F}$ are defined by area with $T_{\mathrm{B} 11}<210,235$, and $273 \mathrm{~K}$ shown by black contours. (f) Vertical profiles of $20-\mathrm{dBZ}$ area (solid line) and the maximum reflectivity (dashed line) of the large RPPF defined in (b). The dash line in (a)-(e) is the edge of the PR swath. Note that there could be a truncation effect due to the narrow PR swath in defining large features (Nesbitt et al. 2006).

into properties of features with file size of, on average, 2.8 megabytes, a reduction in data volume by a factor of 72. After all features are defined from level-1 orbital products, they are combined into monthly files in HDF4 format as level-2 products.

\section{c. Level 3: Generating climatological descriptions from cloud and precipitation features}

It is useful to have characteristics of individual clouds and precipitation systems in level 2 data. It is also im-

TABLE 2. Some parameters of the largest features differently defined in Figs. 3a-e. Note that because of the 2A12 missing rain rate in the center of the system, TPF has lower values of total rain volume and missed the highest echo top of the system.

\begin{tabular}{|c|c|c|c|c|c|c|c|}
\hline Feature definition & RPF & TPF & $\mathrm{RPPF}$ & PCTF & $\mathrm{C} 210 \mathrm{~F}$ & $\mathrm{C} 235 \mathrm{~F}$ & $\mathrm{C} 273 \mathrm{~F}$ \\
\hline Lon $\left(^{\circ}\right)$ & -97.5 & -97.0 & -96.8 & -97.4 & -97.2 & -95.7 & -95.3 \\
\hline Lat $\left(^{\circ}\right)$ & 34.2 & 34.5 & 34.5 & 34.2 & 34.4 & 35.0 & 35.0 \\
\hline Area $\left(\mathrm{km}^{2}\right)$ & 4605 & 14694 & 22167 & 8189 & 14640 & 58885 & 79080 \\
\hline $2 \mathrm{~A} 25$ volumetric rain $\left(\mathrm{mm} \mathrm{h}^{-1} \mathrm{~km}^{2}\right)$ & 44963 & 13534 & 65766 & 45090 & 44710 & 112211 & 113236 \\
\hline $2 \mathrm{~A} 12$ volume rain $\left(\mathrm{mm} \mathrm{h}^{-1} \mathrm{~km}^{2}\right)$ & 98053 & 135469 & 196577 & 118071 & 127791 & 364781 & 367949 \\
\hline Raining area fraction (\%) & 100 & 29 & 39 & 60 & 38 & 26 & 20 \\
\hline Convective raining area fraction (\%) & 70 & 31 & 58 & 69 & 62 & 53 & 54 \\
\hline Convective rain volume fraction ( $\%)$ & 97 & 87 & 96 & 97 & 96 & 95 & 95 \\
\hline Min $85-\mathrm{GHz}$ PCT $(\mathrm{K})$ & 50.3 & 66.8 & 50.3 & 50.3 & 50.3 & 50.3 & 50.3 \\
\hline $\operatorname{Min} T_{\mathrm{B} 11}(\mathrm{~K})$ & 190.3 & 193.8 & 187.0 & 190.3 & 190.3 & 187.0 & 187.0 \\
\hline Max storm height (K) & 18.4 & 16.1 & 18.8 & 18.4 & 18.4 & 18.7 & 18.7 \\
\hline Flash counts (No.) & 400 & 264 & 514 & 434 & 427 & 636 & 636 \\
\hline
\end{tabular}


TRMM $3 A 25$ monthly rain ( $\mathrm{mm} /$ month)
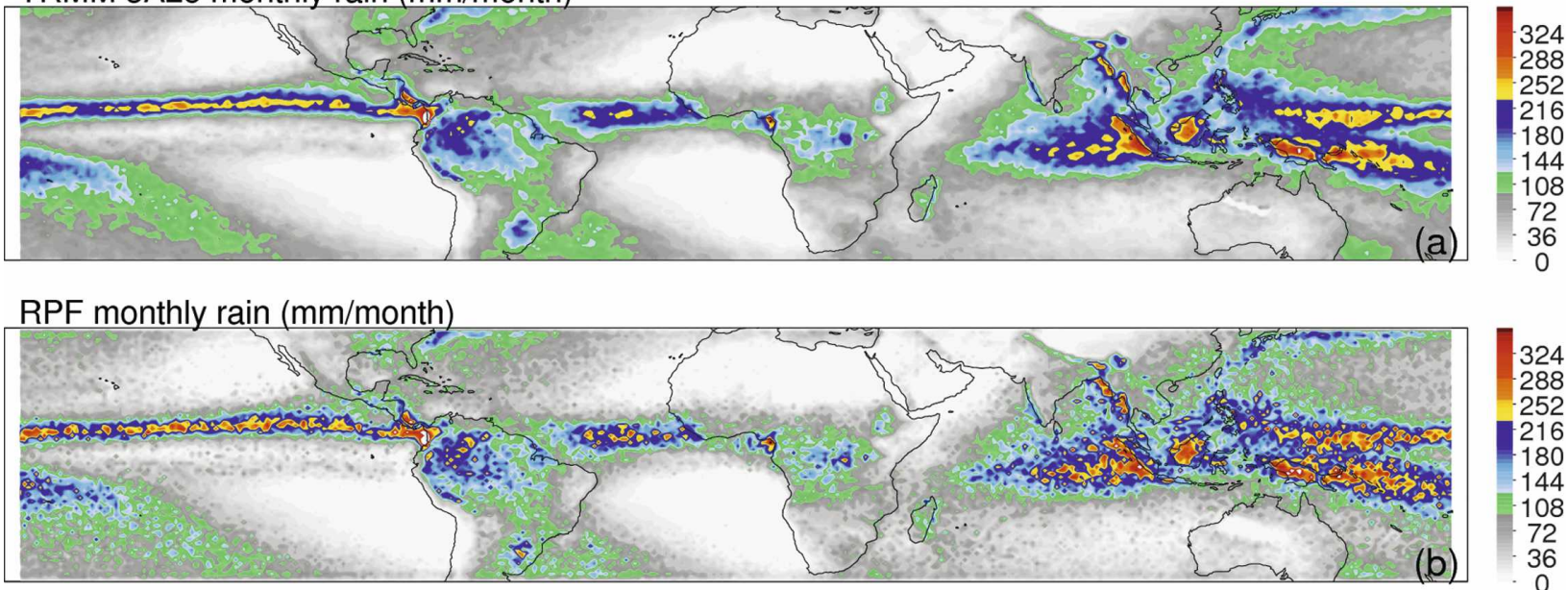

(a)-(b)

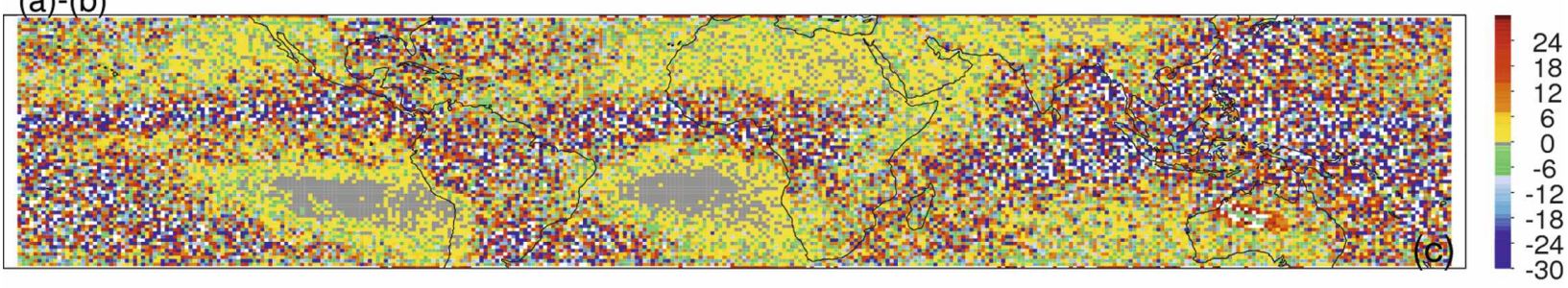

(a)-(b) after degraded to $4^{\circ} \times 4^{\circ}$ resolution

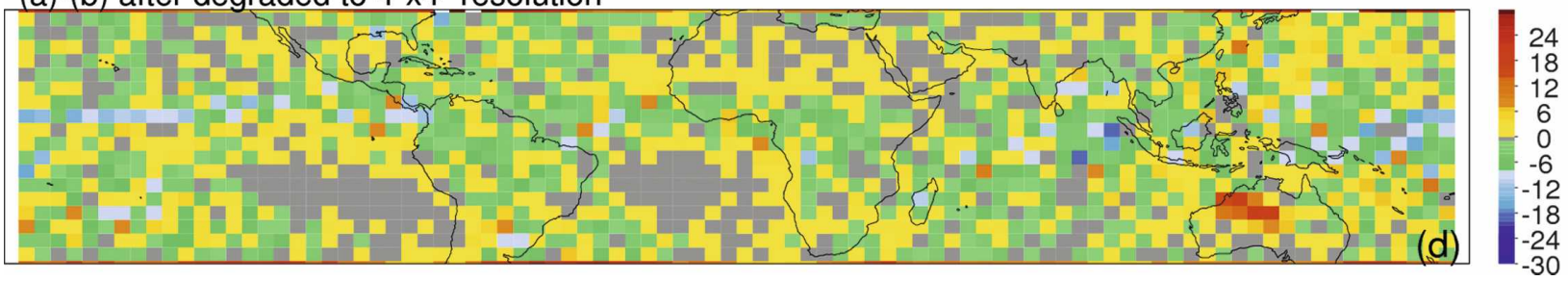

FIG. 4. (a) Mean TRMM 3A25 monthly rainfall from 1998 to 2006. (b) Mean monthly rainfall from RPFs from 1998 to 2006. (c) Differences between (a) and (b). (d) Differences between (a) and (b) after degrading them to $4^{\circ} \times 4^{\circ}$ resolution. Negative values in (c) and (d) imply that more large precipitation systems are centered in the box so that the rainfall from nearby boxes has been counted. Positive values in (c) and (d) imply that part of the rainfall in the box is from the large precipitation systems centered at nearby locations.

portant to study the climatological characteristics of these systems. For this purpose, we summarize the statistics of feature properties, such as the total volumetric rain, the maximum reflectivity found over a specific region, and so on, onto a $1^{\circ} \times 1^{\circ}$ grid. Because TRMM observations include information about the diurnal variation of properties of cloud and precipitation systems, they are categorized into eight local time periods.

Note that when we accumulate the rain volume from features onto the grids, volumetric rain and area inside each feature are assigned to the grid where the massweighted centroid of that feature is located. This could be problematic when we assign volumetric rain and raining area from large cloud and precipitation features to a small grid. However, given enough samples, this problem is minimized to some extent. As shown in Fig. 4 , the general pattern of monthly rainfall by counting the raining pixels inside the grids (3A25) and that by accumulating rain volume of precipitation features centered inside the grids are very close. The differences between the two become smaller when using larger grids (Fig. 4d). However, this problem is noticeable when large systems systemically center at certain locations over some regions, such as Panama and Argentina (Fig. 4d).

To compare with the precipitation estimates from other sources, besides the parameters summarized from features, we also combined TRMM 3B43, 3A25 (gridded monthly rainfall from 2A25), and 3A12 (gridded monthly rainfall from $2 \mathrm{~A} 12$ ) precipitation products, 
and the rainfall estimates from the Geostationary Operational Environmental Satellite precipitation index (GPI; Joyce and Arkin 1997), Global Precipitation Climatology Centre (GPCC; Rudolf 1995), and the Global Precipitation Climatology Project (GPCP; Huffman et al. 2001) onto the same grid. Then level-3 data are produced with all different rainfall estimates and statistically summarized properties of features. Some major parameters calculated in level-3 monthly products are listed below [details are found in Liu (2007)]:

- monthly rainfall estimates from GPI, GPCC, GPCP, and TRMM 3B43, 3A25, and 2A25 and 2A12 rain volume inside the features, total $2 \mathrm{~A} 25$ convective and stratiform raining area and rain volume, rain volume inside features during eight local times, and total number of PR observations;

- a population of features, including total flash counts, total area of $T_{\mathrm{B} 11}<210,235$, and $273 \mathrm{~K}$, total area of $85-\mathrm{GHz} \mathrm{PCT}<250,200,150$, and $100 \mathrm{~K}$ during eight local times inside features, and total $20-\mathrm{dBZ}$ area at different altitudes;

- and maximum 20-, 30-, and 40-dBZ echo tops, maximum flash counts, maximum reflectivity at different altitudes, minimum $T_{\mathrm{B} 11}$ and minimum 37- and 85$\mathrm{GHz}$ PCT inside a feature during eight local time periods $(0-3,3-6,6-9, \ldots)$.

Level-3 products are processed for monthly, yearly, before-boost (January 1998-July 2001), after-boost (September 2001-December 2006), seasonal (DecemberFebruary, March-May, June-August, and SeptemberNovember), and 9-yr (1998-2006) periods.

\section{d. Impact of the satellite orbit boost}

After the TRMM satellite orbit height was boosted from 350 to $403 \mathrm{~km}$ in August 2001, averaged effective pixel areas in 1B01, 1B11, and 2A25 increased by approximately $15 \%$. In addition, the orbit boost also led to changes in many observed and retrieved properties, such as amount of precipitation (e.g., DeMoss and Bowman 2007). One immediate impact of a larger footprint is a more serious beam-filling problem. One would expect that the TMI and the PR would have lower sensitivity after the boost because a larger footprint has a higher possibility to include background radiance over a nonprecipitating area, while the sensitivity of the PR would decrease as well because of an increased range to target. The height of the lowest PR valid bin above the terrain also increased because of the larger footprint. Larger instrument fields of view may also introduce pre- and postboost inconsistency in the parallax correction and collocation between PR and
TMI. With the availability of more than 10 years of TRMM observations, it is possible to study the longterm change of the properties of the features. How to separate the natural climatic variability from the influences of orbit boost in TRMM measurements is a major challenge. Therefore, research regarding the impact of the boost on the sensitivity of the TRMM instruments is warranted in the future.

\section{Applications}

In this section, we introduce three applications of the 9-yr (1998-2006) TRMM cloud and precipitation feature database.

\section{a. Search engine for the specific cases}

The example (Fig. 3) demonstrated that TRMM level-1 and level-2 products are powerful tools for case studies by providing the collocated observations and the characteristics of the target features. How do we find the interesting cases, however? Besides providing the characteristics of a given event, one immediate use of the level-2 dataset is to search for historical events with certain properties for a given region. For example, how many events were there during the past $9 \mathrm{yr}$ near Panama with at least a $2000-\mathrm{km}^{2}$ PR raining area and 50 flashes observed by LIS? It is easy to answer this question [five mesoscale convective systems (MCSs) from 1998 to 2006 in $80^{\circ}-85^{\circ} \mathrm{W}$ and $8^{\circ}-10^{\circ} \mathrm{N}$ ] by searching through the level- 2 datasets rather than by the almost impossibly lengthy process of looking through all of the orbital pixel-level data. An example of such a searching tool is at the time of writing publicly available online (http://www.met.utah.edu/trmm/) for TRMM-observed MCSs during 1998-2006. Using level-2 products, we may also sort and categorize the defined features, such as the most intense convective storms (Zipser et al. 2006), the rainiest storms, or the coldest clouds.

\section{b. Populations and sizes of cloud and precipitation features and their contribution to rainfall}

One important application of the TRMM cloud and precipitation feature database is to study the rainfall contributed from specific types of precipitation systems. By dividing the total population and rain volume from the selected subset of features by those from all features, the importance of the subset of features to the total rainfall can easily be evaluated. For example, consistent with Nesbitt et al. (2006), precipitation systems having sizes of $2000 \mathrm{~km}^{2}$ or more constitute less than $2 \%$ of the total population of detectable (at least one pixel with $\sim 20 \mathrm{~km}^{2}$ in size) precipitation systems (Fig. 5a), but contribute more than $60 \%$ of total rainfall over 

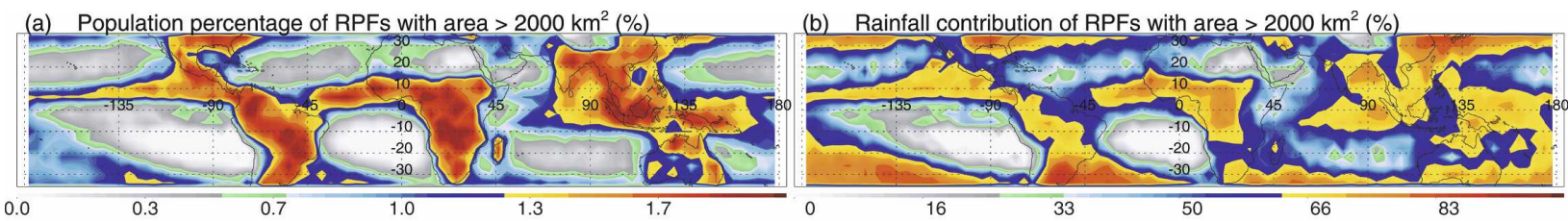

(c) Population percentage of RPFs with flashes (\%)

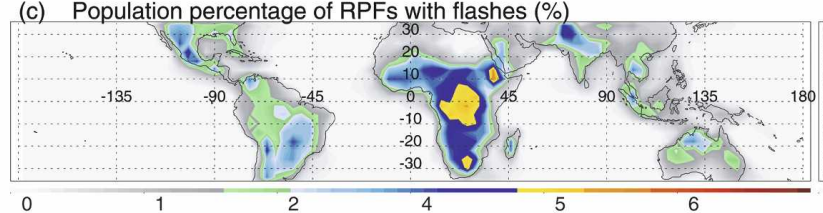

(d) Rainfall contribution of RPFs with flashes (\%)

(e) Population percentage of RPFs with mimnimum $\mathrm{T}_{\mathrm{B} 11}>273 \mathrm{~K}(\%)$
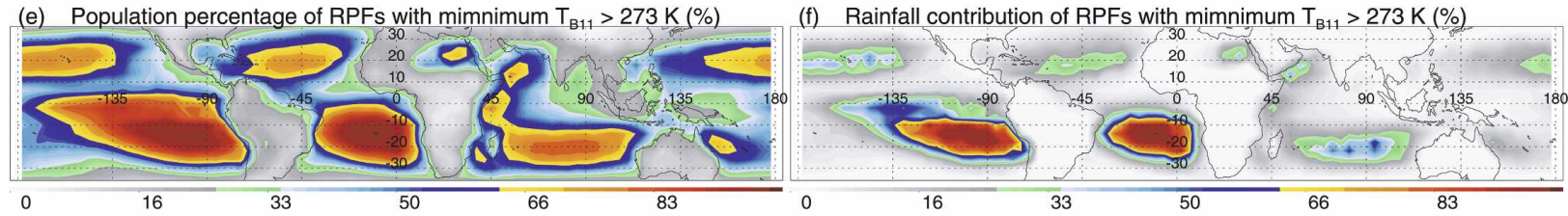

(g) Population percentage of RPFs with mimnimum $\mathrm{T}_{\mathrm{B11}}<210 \mathrm{~K}(\%)$

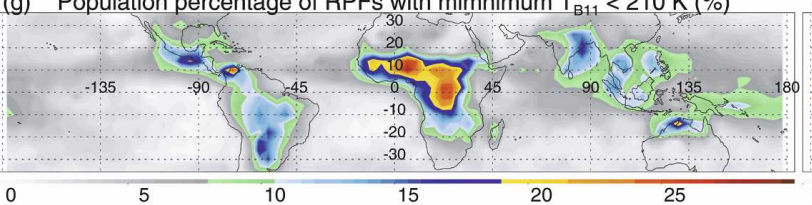

(h) Rainfall contribution under clouds with $\mathrm{T}_{\mathrm{B} 11}<210 \mathrm{~K}(\%)$
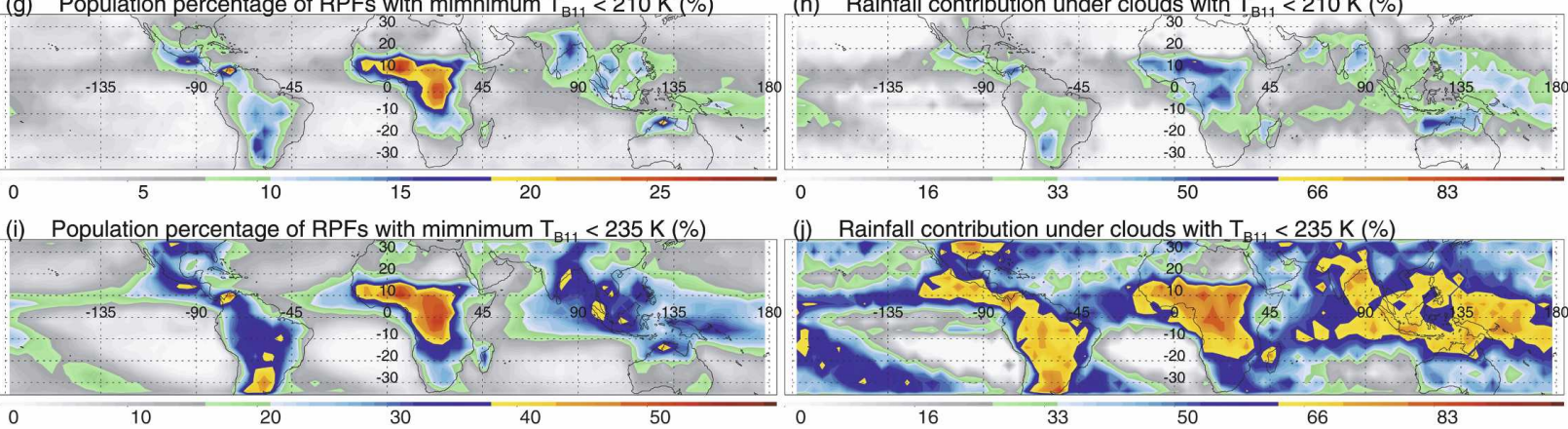

(k) Population percentage of RPFs with mimnimum $85 \mathrm{GHz} P C T<250 \mathrm{~K}(\%$ l) $\quad$ Rainfall contribution from area with $85 \mathrm{GHz} P C T<250 \mathrm{~K}(\%)$
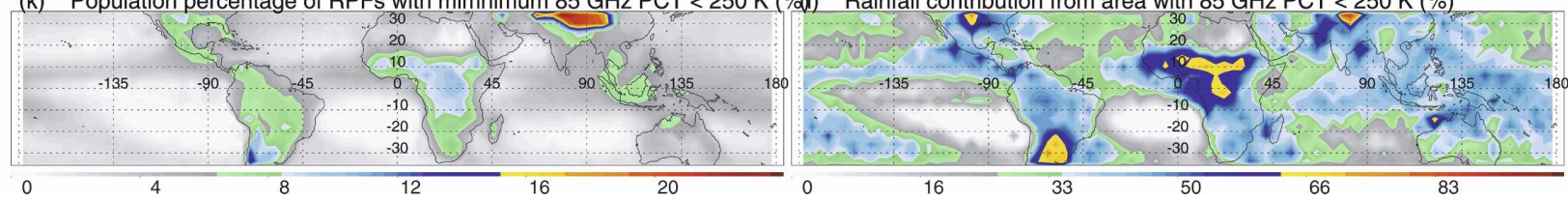

FIG. 5. Distribution of population percentage of selected features to detectable features (of at least one PR pixel in size) and their regional rainfall contributions from TRMM data for 1998-2006. (a) Population percentage of RPFs with size above $2000 \mathrm{~km}^{2}$. (b) Rainfall contribution from 2000- $\mathrm{km}^{2}$ RPFs. (c) Population percentage of RPFs with flashes. (d) Rainfall contribution from RPFs with flashes. (e) Population percentage of RPFs with minimum VIRS $T_{\mathrm{B} 11}>273 \mathrm{~K}$. (f) Rainfall contribution from RPFs with minimum VIRS $T_{\mathrm{B} 11}>273 \mathrm{~K}$. (g) Population percentage of RPFs with minimum VIRS $T_{\mathrm{B} 11}<210 \mathrm{~K}$. (h) Rainfall contribution from area with VIRS $T_{\mathrm{B} 11}<210 \mathrm{~K}$ (rainfall contribution from all C210Fs). (i) Population percentage of RPFs with minimum VIRS $T_{\mathrm{B} 11}<235 \mathrm{~K}$. (j) Rainfall contribution from area with VIRS $T_{\mathrm{B} 11}<235 \mathrm{~K}$ (rainfall contribution from all C235Fs). (k) Population percentage of RPFs with minimum TMI 85-GHz PCT $<250 \mathrm{~K}$. (1) Rainfall contribution from area with TMI 85-GHz PCT $<250 \mathrm{~K}$ (rainfall contribution from all PCTFs). Note that the scales change for (a), (c), (e), (g), (i), and (k).

the most rainy areas of the tropical oceans (Fig. 5b). Over oceans, flashes are rarely seen. However, the subtropical oceanic precipitation systems having flashes contribute around $10 \%$ of total rainfall there (Figs. $5 \mathrm{c}, \mathrm{d})$. Over tropical land, precipitation systems with flashes contribute a larger part of the total rainfall over central Africa than over the Amazon and Indonesia. Shallow and warm raining systems are the main contributors to the rainfall over the less rainy oceanic regions (Figs. 5e,f) (Schumacher and Houze 2003). Very cold cloud tops $\left(T_{\mathrm{B} 11}<210 \mathrm{~K}\right)$ are almost 2 times as likely over central Africa, Panama, northern Australia, and southern Mexico than over the Amazon, and rainfall under these cold clouds is about $50 \%$ of the total over these regions. Over oceans, the western Pacific Ocean is more likely to have very cold clouds (Figs. $5 \mathrm{~g}, \mathrm{~h})$. The original technique of estimating the rainfall from satellite infrared images is to relate the rainfall to the area of $T_{\mathrm{B} 11}$ brightness temperature colder than 235 K (Arkin and Meisner 1987). However, on average, less 
than one-third of precipitation systems over land and less than one-fifth of oceanic systems have minimum cloud-top temperatures colder than $235 \mathrm{~K}$. On average, less than $50 \%$ of the rainfall comes from clouds colder than $235 \mathrm{~K}$ (Figs. 5i,j). There are more precipitation systems with ice-scattering signatures $(85-\mathrm{GHz}$ PCT $<$ $250 \mathrm{~K}$; Spencer et al. 1989) over land than over ocean (Fig. 5k). However, the percentage of rainfall from under the cold PCT area over the Amazon is close to that over most of the ocean (Fig. 51). Notice that in Figs. $5 \mathrm{i}, \mathrm{k}$, there are a large number of RPFs with minimum $T_{\mathrm{B} 11}<235 \mathrm{~K}$ and minimum $85-\mathrm{GHz} \mathrm{PCT}<250 \mathrm{~K}$ over Tibet. Those RPFs are mostly artifacts due to low emissivity at infrared and microwave wavelengths over cold (snow) surfaces.

To demonstrate quantitatively the regional variations of the precipitation feature sizes, intensities, and their contribution to the total rainfall, the cumulative distribution functions (CDFs) of population and rainfall contribution as a function of system size and intensity (defined using minimum PCT) of RPFs are calculated for the selected five regions over land and four regions over ocean (Fig. 6a). Over ocean, the percentage of small-size RPFs (and their corresponding rainfall contributions) is greater than over land. RPFs smaller than $1000 \mathrm{~km}^{2}$ constitute $\sim 90 \%$ of the population but contribute less than $20 \%$ of the rainfall. RPFs greater than $10000 \mathrm{~km}^{2}$ contribute more than $60 \%$ of total rainfall over the South Pacific convergence zone (SPCZ) and approximately $50 \%$ over tropical oceans (Fig. 6b). Based on the convective intensity inferred from the icescattering signature of $85-\mathrm{GHz}$ PCT, oceanic RPFs are convectively weaker than those over land with warmer $85-\mathrm{GHz}$ PCTs. When compared with those of other regions, it is seen that warm RPFs with $85-\mathrm{GHz} \mathrm{PCT}>$ $200 \mathrm{~K}$ over the SPCZ contribute the largest percentage of rainfall (Fig. 6c).

Over land, RPFs greater than $10000 \mathrm{~km}^{2}$ contribute $70 \%$ of total rainfall over Argentina and the southeastern United States and about $40 \%$ over the Amazon. The Congo basin has the greatest percentage of RPFs with intense $85-\mathrm{GHz}$ ice scattering. However, CDFs of rainfall contribution over the Congo, Argentina, and the southeastern United States are very different from those of Amazon and Indonesia; the latter two are closer to CDFs from tropical oceans. RPFs with minimum $85-\mathrm{GHz}$ PCT $<100 \mathrm{~K}(150 \mathrm{~K})$ contribute approximately $15 \%(50 \%)$ of total rainfall over the Congo, Argentina, and the southeastern United States but less than $5 \%(30 \%)$ over the Amazon, Indonesia, and oceans.

By varying the feature definition, a different perspective of precipitation contribution from under cold clouds (e.g., Liu et al. 2007) or systems with cold 85$\mathrm{GHz}$ PCT can be studied. For example, the total rainfall contributions and the contributions from the largest $1 \%$ of features differently defined are listed in Table 3 . The differences between the rainfall contribution from TPFs and RPFs are caused by the different rainfall screening algorithms and by uncertainties in the collocation of TMI and PR pixels. The rainfall under cloud that is colder than $235 \mathrm{~K}$ only contributes $57 \%$ to the total rainfall over the tropics $\left(20^{\circ} \mathrm{S}-20^{\circ} \mathrm{N}\right)$.

\section{c. Regional variations of vertical structure of radar echoes}

Another application of the TRMM feature database is to study the regional variations of vertical structures of precipitation features. Figure 7 shows the $20-\mathrm{dBZ}$ echo occurrence calculated by dividing the $20-\mathrm{dB} Z$ area inside RPPFs at selected heights by the total PR sampled area during 1998-2006. At 2-km height, 20$\mathrm{dB} Z$ echoes occur more frequently over ocean than over land. At $5 \mathrm{~km}, 20-\mathrm{dB} Z$ echoes occur more over the western Pacific and Indonesia than other places. At 9 $\mathrm{km}$, there are more $20-\mathrm{dB} Z$ echoes over land than over ocean. At $13 \mathrm{~km}, 20-\mathrm{dB} Z$ echoes over land dominate (Liu and Zipser 2005).

With a focus on the strong RPPFs with 40-dBZ echo and $1000 \mathrm{~km}^{2}$ in size, the contoured frequency-byaltitude diagrams (CFADs; Yuter and Houze 1995) of $20-\mathrm{dBZ}$ area profiles of these RPPFs from $20^{\circ} \mathrm{S}$ to $20^{\circ} \mathrm{N}$ are shown in Fig. 8. In general, oceanic systems have larger 20-dBZ areas below $2 \mathrm{~km}$ than land systems. However, because of the ground clutter, the $20-\mathrm{dB} Z$ areas below $2 \mathrm{~km}$ over land and below $1.5 \mathrm{~km}$ over ocean may be compromised. Oceanic RPPF 20-dBZ areas decrease faster with altitude than those of land RPPFs above $2 \mathrm{~km}$. One-half of the strong oceanic RPPFs have $100-\mathrm{km}^{2} 20-\mathrm{dBZ}$ areas above $8 \mathrm{~km}$, and one-half of the strong land RPPFs have $100-\mathrm{km}^{2} 20$ $\mathrm{dB} Z$ areas above $9.5 \mathrm{~km}$. It is interesting that between 2 and $4 \mathrm{~km}$ the $20-\mathrm{dB} Z$ area increases with altitude in RPPFs over land while the $20-\mathrm{dB} Z$ area decreases with altitude in RPPFs over ocean.

CFADs of maximum-reflectivity profiles of the RPPFs with $40-\mathrm{dB} Z$ echo and $1000 \mathrm{~km}^{2}$ in size are shown in Fig. 9. Land RPPFs have larger maximum-reflectivity values than oceanic RPPFs at the freezing level (4-5 $\mathrm{km})$. Then the land RPPF maximum-reflectivity values decrease more slowly than oceanic RPPFs above the freezing level, while reaching higher altitudes. One-half of the land (ocean) RPPFs have maximum-reflectivity values of greater than $20 \mathrm{dBZ}$ at $11.5 \mathrm{~km}(10 \mathrm{~km})$. From $2 \mathrm{~km}$ to the freezing level near $5 \mathrm{~km}$, the maximum reflectivity of land RPPFs increases with altitude but 

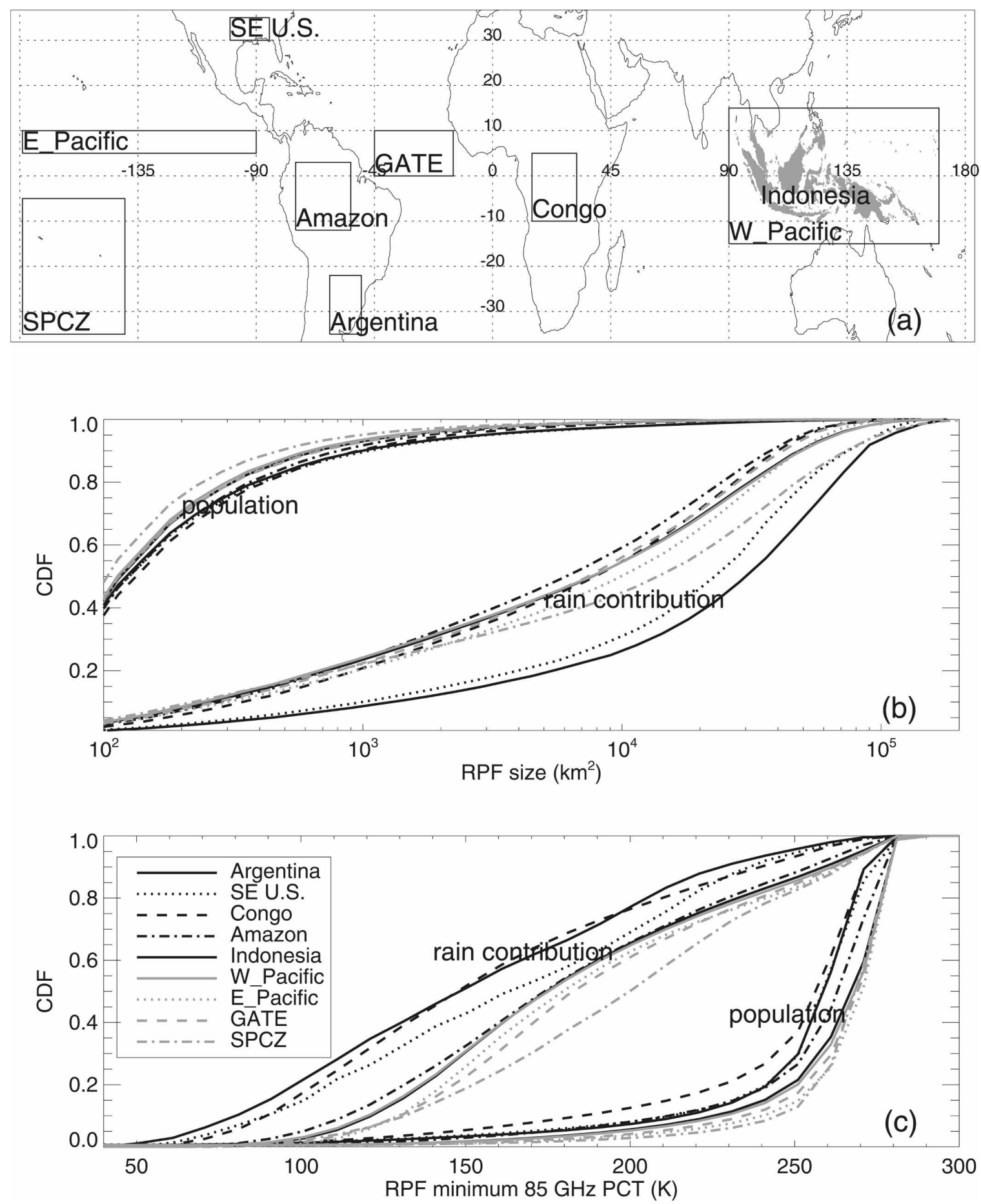

FIG. 6. (a) Map showing selected regions of interest. (b) CDFs of sizes of the RPFs with at least four pixels and their rainfall contribution over the selected regions. (c) CDFs of convective intensity of RPFs with at least four pixels inferred from $85-\mathrm{GHz}$ PCT and their rainfall contribution over the selected regions.

that of the oceanic RPPFs decreases with altitude. This is consistent with the result of the maximum-reflectivity profiles of MCSs described by Zipser and Lutz (1994) using ground-based radar data from a few locations.
To demonstrate regional variations, CFADs of 20$\mathrm{dB} Z$ area and maximum-reflectivity profiles are analyzed for RPPFs containing at least one pixel that is greater than $40-\mathrm{dB} Z$ echo and is $1000 \mathrm{~km}^{2}$ in size in the 
TABLE 3. Contributions to total rainfall over $20^{\circ} \mathrm{S}-20^{\circ} \mathrm{N}$ from all features and from the largest $1 \%$ of features defined differently.

\begin{tabular}{|c|c|c|c|c|c|c|}
\hline$\%$ & $\begin{array}{c}\text { Total } \\
\text { contribution }\end{array}$ & $\begin{array}{l}\text { Contribution } \\
\text { over land }\end{array}$ & $\begin{array}{c}\text { Contribution } \\
\text { over ocean }\end{array}$ & $\begin{array}{c}\text { Contribution from } \\
\text { the largest } 1 \%\end{array}$ & $\begin{array}{c}\text { Largest } 1 \% \\
\text { over land }\end{array}$ & $\begin{array}{l}\text { Largest } 1 \% \\
\text { over ocean }\end{array}$ \\
\hline RPF & 100 & 100 & 100 & 66 & 59 & 67 \\
\hline TPF & 74 & 68 & 75 & 42 & 30 & 46 \\
\hline PCTF & 37 & 40 & 36 & 13 & 12 & 13 \\
\hline $\mathrm{C} 210 \mathrm{~F}$ & 25 & 27 & 24 & 11 & 10 & 11 \\
\hline $\mathrm{C} 235 \mathrm{~F}$ & 57 & 61 & 55 & 39 & 36 & 40 \\
\hline $\mathrm{C} 273 \mathrm{~F}$ & 83 & 92 & 80 & 72 & 78 & 69 \\
\hline
\end{tabular}
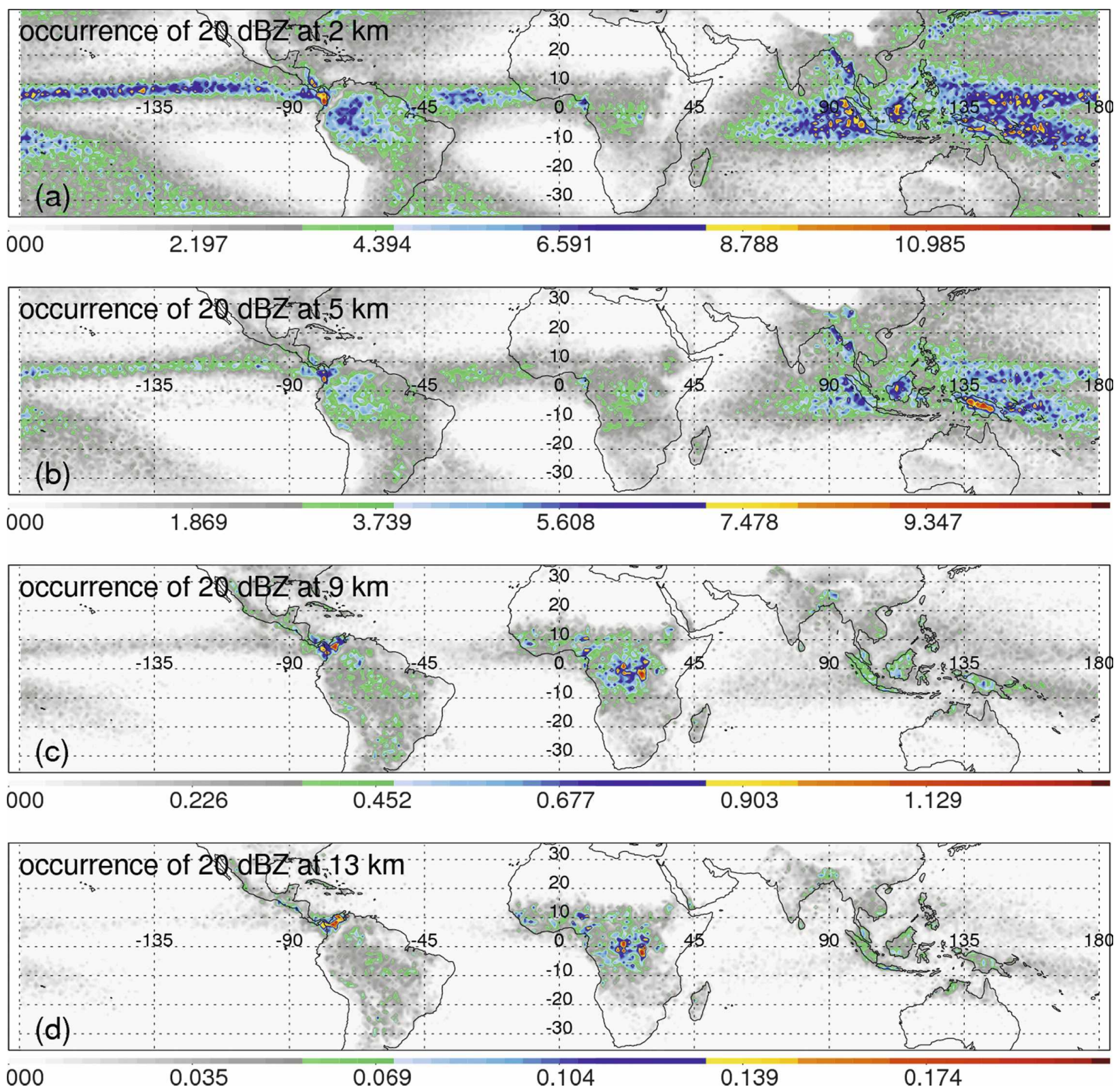

FIG. 7. Occurrence of PR radar reflectivity above $20 \mathrm{dBZ}$ (\%) at (a) 2, (b) 5, (c) 9, and (d) $13 \mathrm{~km}$. The areas of $20 \mathrm{dBZ}$ are summarized from RPPFs in 1998-2006. Note that these heights are above the Earth ellipsoid, and so (a) cannot have echoes in regions of moderate terrain. Note that the scales are different for (a)-(d). 

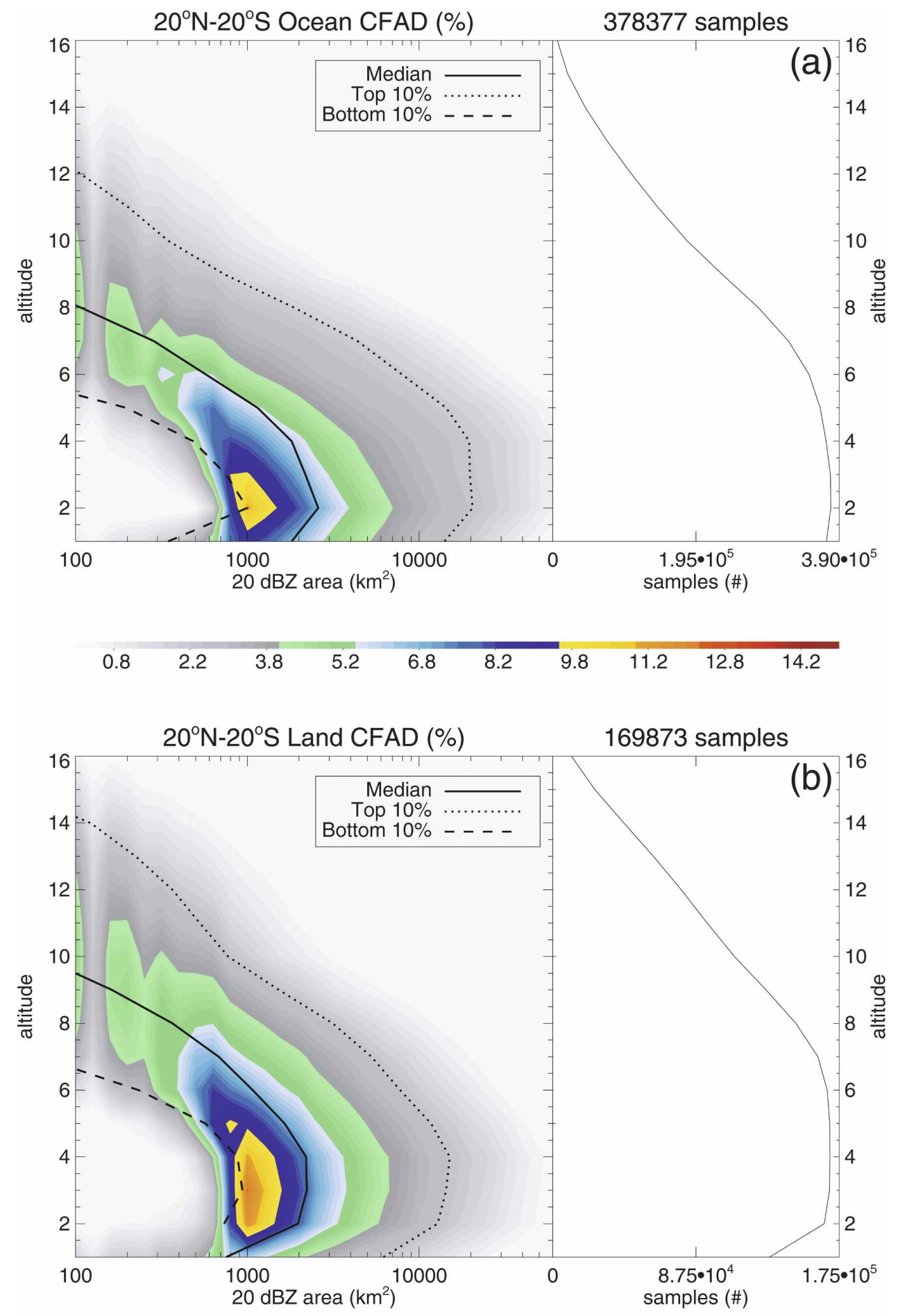

$\begin{array}{llllllllll}0.8 & 2.2 & 3.8 & 5.2 & 6.8 & 8.2 & 9.8 & 11.2 & 12.8 & 14.2\end{array}$

FIG. 8. (a) Frequency of $20-\mathrm{dB} Z$ area at different altitudes from 1998 to 2005 for $20^{\circ} \mathrm{N}-20^{\circ} \mathrm{S}$ oceanic RPPFs with at least one $40-\mathrm{dBZ}$ pixel and $1000-\mathrm{km}^{2}$ raining area. Median (solid line), top $10 \%$ (dotted line), and bottom $10 \%$ (dashed line) of $20-\mathrm{dB} Z$ area values at different altitudes are shown. The frequency is calculated by determining the histogram of the area of all RPPFs (including those with $0-\mathrm{km}^{2}$ area) at each altitude level. The vertical profile at the right shows the total number of nonzero RPPF samples with $20 \mathrm{dBZ}$ at different altitudes. (b) As in (a), but for the RPPFs over land. 


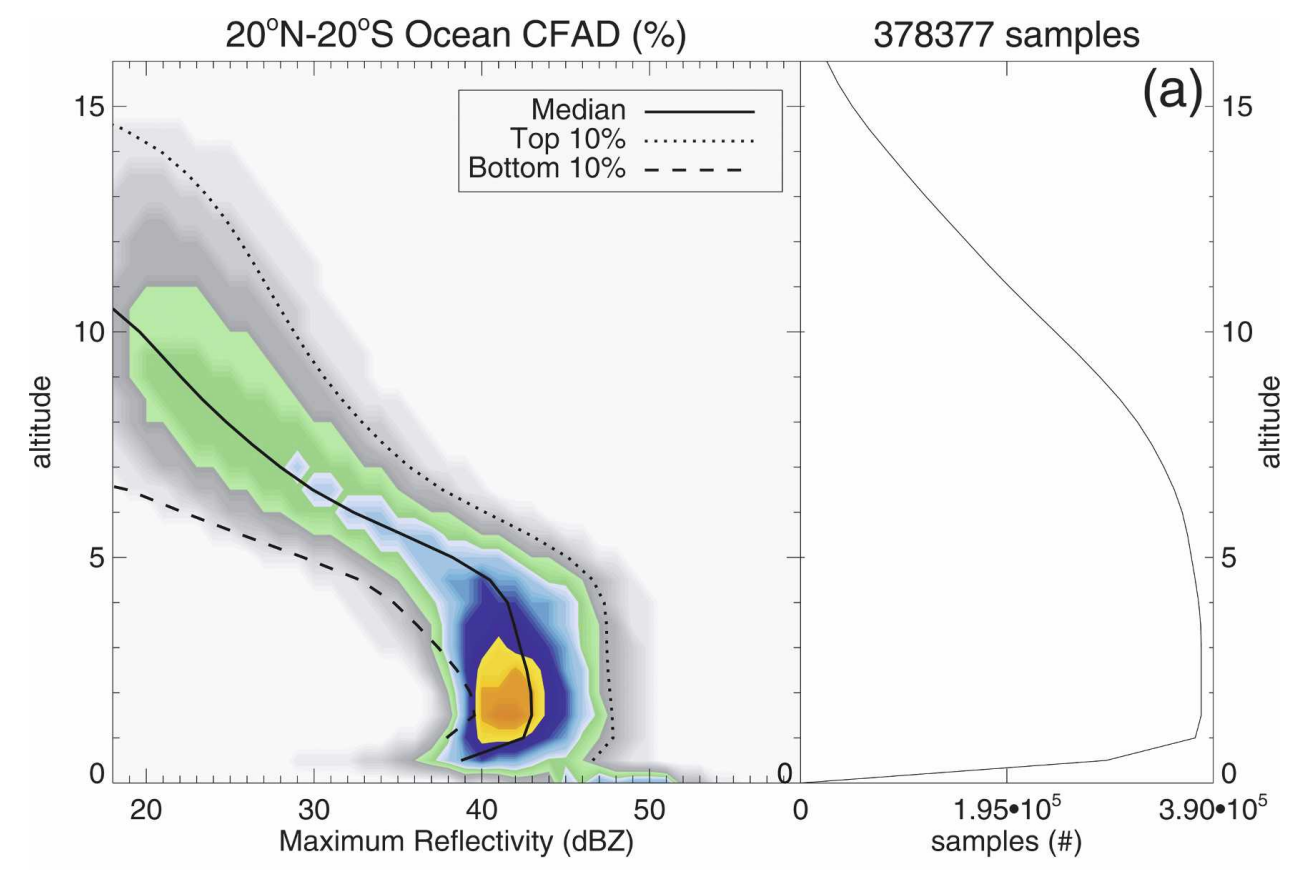

$\begin{array}{llllllllll}0.8 & 2.2 & 3.8 & 5.2 & 6.8 & 8.2 & 9.8 & 11.2 & 12.8 & 14.2\end{array}$

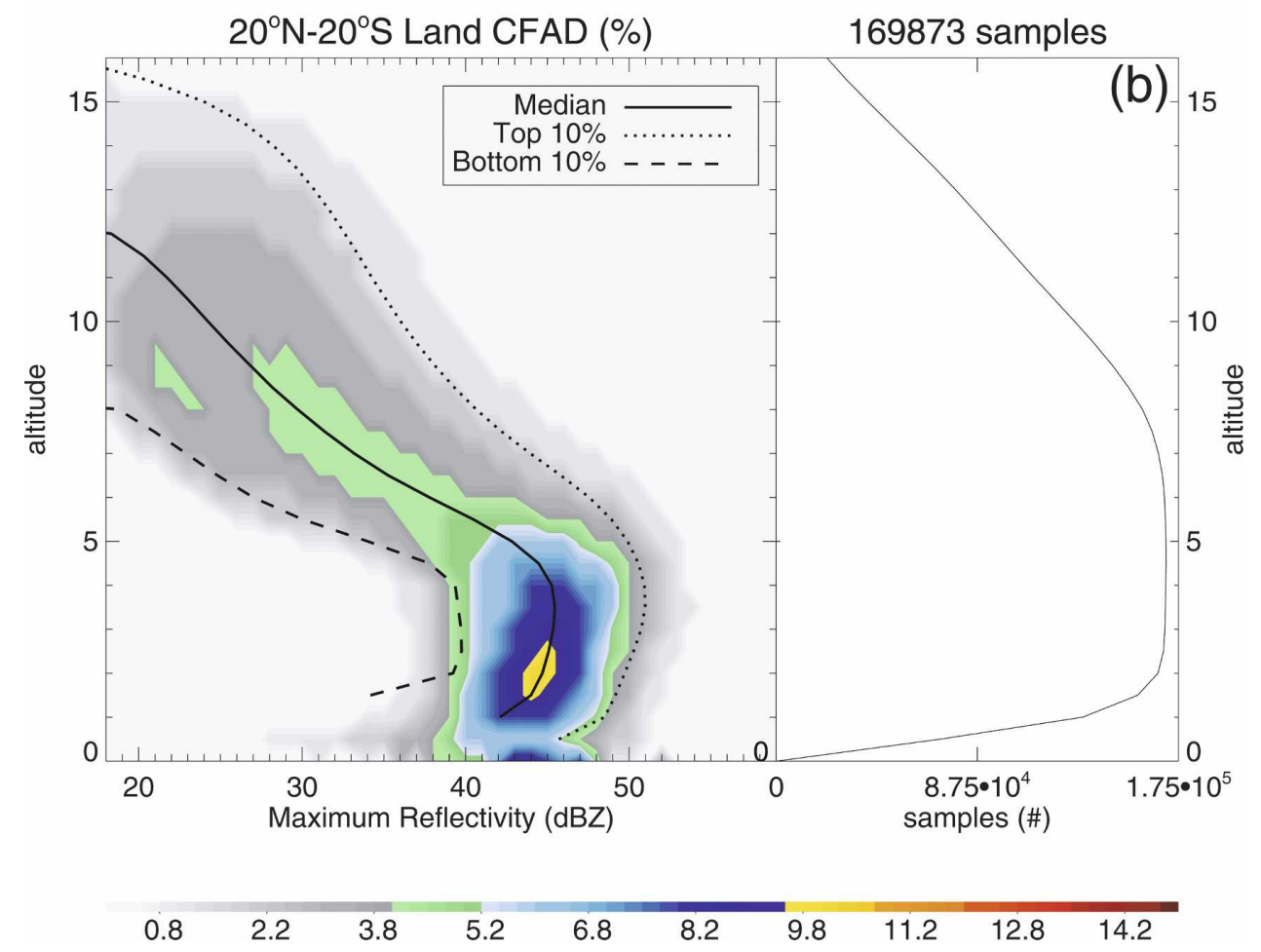

FIG. 9. (a) Frequency of maximum reflectivity at different altitudes from 1998 to 2005 for $20^{\circ} \mathrm{N}-20^{\circ} \mathrm{S}$ oceanic RPPFs with at least one $40-\mathrm{dBZ}$ pixel and $1000-\mathrm{km}^{2}$ raining area. Median (solid line), top $10 \%$ (dotted line), and bottom $10 \%$ (dashed line) of maximum-reflectivity values at different altitudes are shown. The frequency is calculated by determining the histogram of the area of all RPPFs (including those without echoes) at each altitude level. The vertical profile at the right shows the total number of nonzero RPPF samples at different altitudes. (b) As in (a), but for the RPPFs over land. Note that the number of samples decreases sharply because of ground clutter contamination below $1.5 \mathrm{~km}$ over ocean and below $2 \mathrm{~km}$ over land. 

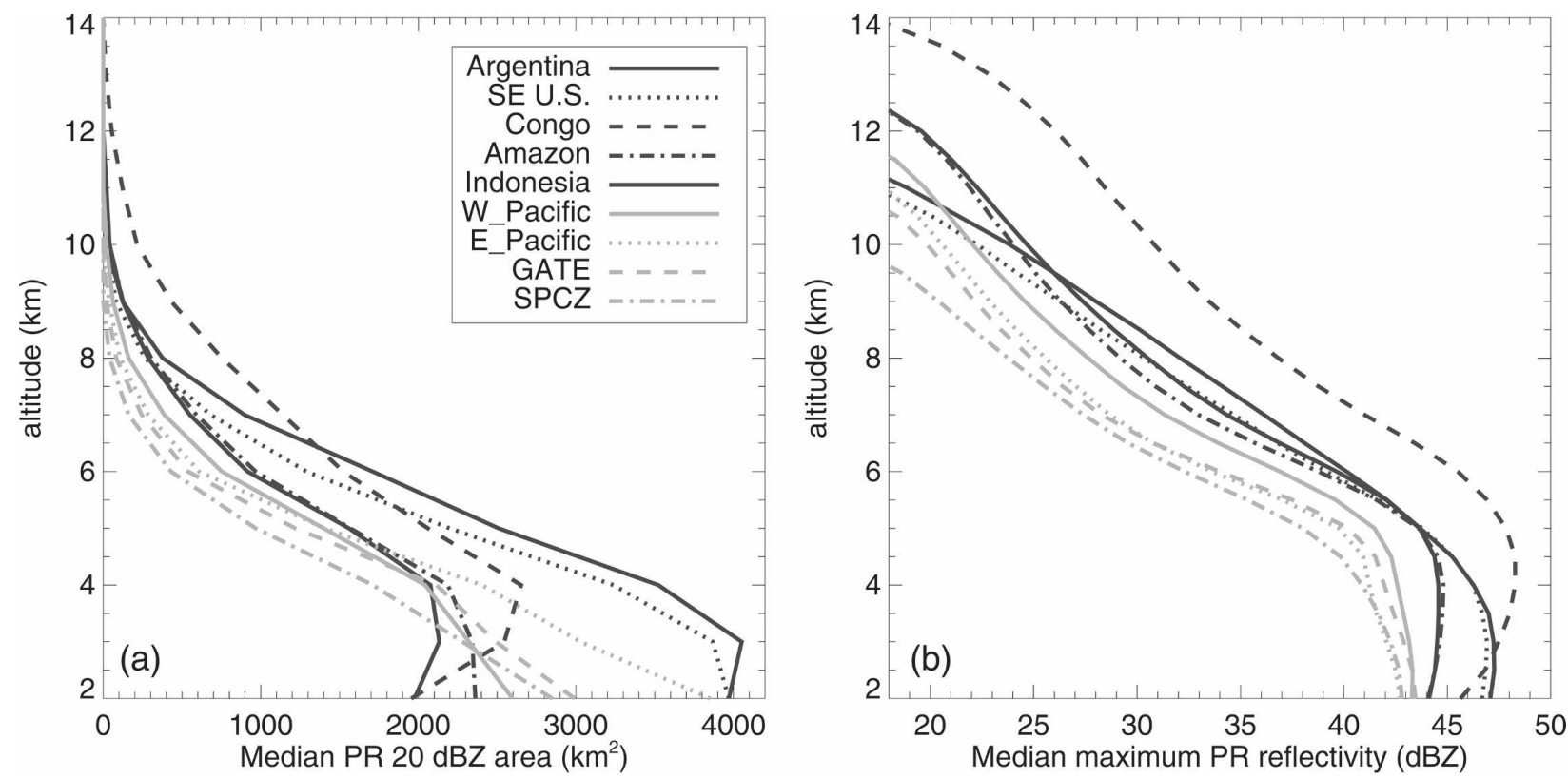

FIG. 10. (a) Median values of maximum-reflectivity profiles from 1998 to 2006 for RPPFs inside the selected regions shown in Fig. 6a. The median values are calculated in the same way as the solid line shown in the left panel of Fig. 8a but from the RPPFs in the selected regions. (b) As in (a), but for the median values from $20-\mathrm{dBZ}$ area profiles.

selected regions shown in Fig. 6a. The median profiles of those CFADs are compared in Fig. 10. Above the freezing level, land RPPFs have larger 20-dBZ area and reach higher altitudes than oceanic RPPFs. On average, RPPFs over the Congo basin are the tallest, strongest (Zipser et al. 2006), and the largest in the tropics. Extratropical systems in the southeastern United States and Argentina are even larger. From $2 \mathrm{~km}$ to the freezing level, maximum reflectivity and the $20-\mathrm{dB} Z$ area of oceanic RPPFs decrease with altitude, in contrast to the RPPFs in all land regions. The southeastern United States and Argentina's RPPFs have larger 20-dBZ areas and stronger reflectivity near $2 \mathrm{~km}$. The Congo has the largest increase of maximum reflectivity and 20$\mathrm{dB} Z$ area from $2 \mathrm{~km}$ to the freezing level. This may be explained by strong evaporation below clouds over the region (McCollum et al. 2000; Geerts and Dejene 2005). Acting similar to a "green ocean" (Silva Dias et al. 2002), the Amazon has the smallest increase of maximum reflectivity and a slight decrease of $20-\mathrm{dB} Z$ area from $2 \mathrm{~km}$ to the freezing level.

One additional factor that has to be considered when interpreting Figs. 9 and 10 is the PR's attenuation (and its correction), which increases toward the surface at greater range from the radar. Reflectivity may be attenuated severely under the strongest convective cores, and so any errors in the attenuation correction algorithm for the PR would lead to increased uncertainty in determining maximum reflectivities at lower altitudes.
Based on this reasoning, however, projected areas of 20 $\mathrm{dB} Z$ should be influenced to a much lesser extent.

\section{Summary}

This paper introduces the construction and applications of a database containing cloud and precipitation features identified from measurements of radar and visible, infrared, and microwave radiometers on the TRMM satellite. First, the measurements from different instruments are collocated and level-1 products are generated with common coordinates for the different measurements. Then by defining the cloud and precipitation features in level-2 products, original information of pixel-level measurements is compressed into the characteristics of features, which may easily be used to index the observed events. This increases substantially the efficiency of searching and sorting the observed historical events. The level-3 products are generated by summarizing the characteristics of features onto $1^{\circ} \times 1^{\circ}$ grids and provide useful climatological descriptions of rainfall and properties of the contributing cloud and precipitation systems.

Besides indexing the cloud and precipitation features, two applications of examining rainfall contribution and regional differences of vertical structure of convection are explored by using the feature database. There are many other possible studies, such as validation of rainfall retrieval algorithms from PR and TMI 
measurements, differences among the diurnal cycles of lightning, cloud coverage, and precipitation, and validation of properties of convection and convective systems in climate models. Those topics will be discussed in future studies.

In all, we introduced a method of analyzing the measurements from multiple instruments onTRMM by defining multiple types of features to summarize the information of the observed event. The general framework of this method can be applied to other multiple instrument measurements, such as observations from the A-Train, which consist of data from several satellites flying on the same orbital path, often measuring the same objects.

Acknowledgments. This research was supported by NASA Precipitation Measurement Mission Grants NAG5-13628 and NN-H-06-Z-DA-001-N to CL and EZ under the direction of Dr. Ramesh Kakar. Special thanks are given to Drs. Erich Stocker and John Kwiatkowski and the rest of the TRMM Science Data and Information System (TDSIS) at NASA Goddard Space Flight Center, Greenbelt, MD, for data processing assistance.

\section{REFERENCES}

Arkin, P. A., and B. N. Meisner, 1987: The relationship between large-scale convective rainfall and cold cloud over the Western Hemisphere during 1982-84. Mon. Wea. Rev., 115, 51-74.

Awaka, J., T. Iguchi, and K. Okamoto, 1998: Early results on rain type classification by the Tropical Rainfall Measuring Mission (TRMM) precipitation radar. Proc. Eighth URSI Commission F Triennial Open Symp., Aveiro, Portugal, International Union of Radio Science, 143-146.

Cecil, D. J., S. J. Goodman, D. J. Boccippio, E. J. Zipser, and S. W. Nesbitt, 2005: Three years of TRMM precipitation features. Part I: Radar, radiometric, and lightning characteristics. Mon. Wea. Rev., 133, 543-566.

Chen, S., R. A. Houze Jr., and B. E. Mapes, 1996: Multiscale variability of deep convection in relation to large-scale circulation in TOGA COARE. J. Atmos. Sci., 53, 1380-1409.

Cifelli, R., S. W. Nesbitt, S. A. Rutledge, W. A. Petersen, and S. Yuter, 2007: Radar characteristics of precipitation features in the EPIC and TEPPS regions of the east Pacific. Mon. Wea. Rev., 135, 1576-1595.

DeMoss, J. D., and K. P. Bowman, 2007: Changes in TRMM rainfall due to the orbit boost estimated from buoy rain gauge data. J. Atmos. Oceanic Technol., 24, 1598-1607.

Geerts, B., 1998: Mesoscale convective systems in the southeast United States during 1994-95: A survey. Wea. Forecasting, 13, 860-869.

— vertical structure of precipitation systems in Africa based on spaceborne radar data. J. Climate., 18, 893-916.

Huffman, G., R. Adler, M. Morrissey, D. Bolvin, S. Cuttis, R. Joyce, B. McGavock, and J. Susskind, 2001: Global precipi- tation at one-degree daily resolution from multisatellite observations. J. Hydrometeor., 2, 36-50.

Iguchi, T., T. Kozu, R. Meneghini, J. Awaka, and K. Okamoto, 2000: Rain-profiling algorithm for the TRMM precipitation radar. J. Appl. Meteor., 39, 2038-2052.

Joyce, R., and P. A. Arkin, 1997: Improved estimates of tropical and subtropical precipitation using the GOES precipitation index. J. Atmos. Oceanic Technol., 10, 997-1011.

Kalnay, E., and Coauthors, 1996: The NCEP/NCAR 40-Year Reanalysis Project. Bull. Amer. Meteor. Soc., 77, 437-471.

Kistler, R., and Coauthors, 2001: The NCEP-NCAR 50-Year Reanalysis: Monthly means CD-ROM and documentation. Bull. Amer. Meteor. Soc., 82, 247-267.

Kummerow, C., W. Barnes, T. Kozu, J. Shiue, and J. Simpson, 1998: The Tropical Rainfall Measuring Mission (TRMM) sensor package. J. Atmos. Oceanic Technol., 15, 809-817.

— , and Coauthors, 2001: The evolution of the Goddard profiling algorithm (GPROF) for rainfall estimation from passive microwave sensors. J. Appl. Meteor., 40, 1801-1820.

Liu, C., cited 2007: University of Utah TRMM precipitation and cloud feature database description, v1.0. [Available online at http://www.met.utah.edu/trmm/TRMM_database_ description_v1.0.pdf.]

_ , and E. J. Zipser, 2005: Global distribution of convection penetrating the tropical tropopause. J. Geophys. Res., 110, D23104, doi:10.1029/2005JD006063.

— , E. Zipser, and S. W. Nesbitt, 2007: Global distribution of tropical deep convection: Different perspectives from TRMM infrared and radar data. J. Climate, 20, 489-503.

Liu, G., J. A. Curry, and R. Sheu, 1995: Classification of clouds over the western equatorial Pacific Ocean using combined infrared and microwave satellite data. J. Geophys. Res., 100, 13 811-13 826.

Mapes, B. E., and R. A. Houze, 1992: Cloud clusters and superclusters over the oceanic warm pool. Mon. Wea. Rev., 121, 1398-1416.

McCollum, J., A. Gruber, and M. B. Ba, 2000: Discrepancy between gauges and satellite estimates of rainfall in equatorial Africa. J. Appl. Meteor., 39, 666-679.

Mohr, K. I., and E. J. Zipser, 1996: Mesoscale convective systems defined by their $85-\mathrm{GHz}$ ice scattering signature: Size and intensity comparison over tropical oceans and continents. Mon. Wea. Rev., 124, 2417-2437.

Nesbitt, S. W., and E. J. Zipser, 2003: The diurnal cycle of rainfall and convective intensity according to three years of TRMM measurements. J. Climate, 16, 1456-1475.

,-- , and D. J. Cecil, 2000: A census of precipitation features in the tropics using TRMM: Radar, ice scattering, and lightning observations. J. Climate, 13, 4087-4106.

—, R. Cifelli, and S. A. Rutledge, 2006: Storm morphology and rainfall characteristics of TRMM precipitation features. Mon. Wea. Rev., 134, 2702-2721.

Rudolf, B., 1995: The global climate system review: Climate system monitoring June 1991-November 1993. WMO No. 819, $150 \mathrm{pp}$.

Schumacher, C., and R. A. Houze Jr., 2003: The TRMM precipitation radar's view of shallow, isolated rain. J. Appl. Meteor., 42, 1519-1524. 
Silva Dias, M. A. F., and Coauthors, 2002: Cloud and rain processes in a biosphere-atmosphere interaction context in the Amazon region. J. Geophys. Res., 107, 8072, doi:10.1029/ 2001JD000335.

Spencer, R. W., H. G. Goodman, and R. E. Hood, 1989: Precipitation retrieval over land and ocean with the SSM/I: Identification and characteristics of the scattering signal. J. Atmos. Oceanic Technol., 6, 254-273.

Steiner, M., R. A. Houze Jr., and S. Yuter, 1995: Climatological characterization of three-dimension storm structure from operational radar and rain gauge data. J. Appl. Meteor., 34, 1978-2007.

Stephens, G. L., and Coauthors, 2002: The CloudSat mission and the A-TRAIN. Bull. Amer. Meteor. Soc., 83, 1771-1790.
Toracinta, E. R., and E. J. Zipser, 2001: Lightning and SSM/I-icescattering mesoscale convective systems in the global tropics. J. Appl. Meteor., 40, 983-1002.

Yuter, S. E., and R. A. Houze, 1995: Three-dimensional kinematic and microphysical evolution of Florida cumulonimbus. Part II: Frequency distributions of vertical velocity, reflectivity, and differential reflectivity. Mon. Wea. Rev., 123, 1941-1963.

Zipser, E. J., and K. R. Lutz, 1994: The vertical profile of radar reflectivity of convective cells: A strong indicator of storm intensity and lightning probability? Mon. Wea. Rev., 122, 1751-1759.

—, D. Cecil, C. Liu, S. Nesbitt, and D. Yorty, 2006: Where are the most intense thunder storms on Earth? Bull. Amer. Meteor. Soc., 87, 1057-1071. 